\title{
Erratum to: Mechanistic insight of platelet apoptosis leading to non-surgical bleeding among heart failure patients supported by continuous-flow left ventricular assist devices
}

\author{
Nandan K. Mondal ${ }^{1,2} \cdot$ Tieluo $\mathrm{Li}^{2} \cdot$ Zengsheng Chen ${ }^{1} \cdot$ Hegang H. Chen ${ }^{3}$. \\ Erik N. Sorensen $^{4} \cdot$ Si M. Pham ${ }^{2} \cdot$ Michael A. Sobieski ${ }^{1} \cdot$ Steven C. Koenig ${ }^{1}$. \\ Mark S. Slaughter $^{1} \cdot$ Bartley P. Griffith $^{2} \cdot$ Zhongjun J. Wu $^{1,2}$
}

Published online: 2 August 2017

(C) Springer Science+Business Media, LLC 2017

\section{Erratum to: Mol Cell Biochem \\ DOI 10.1007/s11010-017-3021-1}

In the original publication of the article, second author's name was misspelt. The correct name is given in this erratum.

The original article was corrected.

The online version of the original article can be found under doi:10.1007/s11010-017-3021-1.

Zhongjun J. Wu

zwu@som.umaryland.edu

1 Department of Cardiovascular and Thoracic Surgery,

Cardiovascular Innovation Institute, University of Louisville School of Medicine, Louisville, KY, USA

2 Department of Surgery, Artificial Organs Laboratory, University of Maryland School of Medicine, 10 South Pine Street, MSTF 434A, Baltimore, MD 21201, USA

3 Department of Epidemiology and Public Health, University of Maryland School of Medicine, Baltimore, MD, USA

4 Department of Clinical Engineering, University of Maryland Medical Center, Baltimore, MD, USA 